\title{
'WASTAGE' IS A CHALLENGE OF TRIBAL EDUCATION -A REVIEW BASED STUDY
}

\author{
Abhisek Panda \\ Student of RIE, Bhubaneswar
}

\author{
Laxmipriya Ojha \\ Guest faculty, DIET, Puri, Odisha
}

Article DOI: https://doi.org/10.36713/epra6062

\begin{abstract}
India is a motherland of large number diverse communities. Tribes are called as 'Adivasi' or socially backward class people mainly lives in forest, hills, and rural remote area. There are more than $8.6 \%$ of total population (Wikipedia) are tribes with around 645 tribes communities in India. In the question of tribal education a huge number of students are out of school, the literacy rate is below of national average literacy and significant literacy gap is found among the tribal male and female. So, in this juncture the objectives of this review based study are a comprehensive understanding regarding the Tribal dropout based on the existing literature reporting govt. initiatives and reasons of dropout in India. The study identified many reasons behind the dropout and explored equity and equality related issues faces challenges and a huge number of tribal children are out of school and deprived from accessing quality education
\end{abstract}

\section{INTRODUCTION}

Education is a powerful weapon by which we can eradicate the all types of social and economical barrier can help for the upliftment of the society, man making as well as the development of the nation. According to Nelson Mandela "Education is the most powerful weapon which you can use to change the World"

India is a motherland of a large number of tribal peoples with a diverse of socio economical background. Tribes are called as 'Adivasi' or socially backward class people mainly lives in forest, hills, and rural remote area. There are more than $8.6 \%$ of total population (Wikipedia) are tribes with around 645 tribes communities in India. Many of them isolated themselves within their conservative culture (North Sentinel) and many of them trying to adopt the modern science and technology and enhance their culture and life by accessing the quality education. Some times its have a adverse effect. As a example Annamalai (1999) explained that how tribals loose their skill by so much depending on govt. Andamanese tribal forgot their fishing skill and boat making skill which they learned informally generation by generation, now waiting for speed boat if they want to go portblair In the field of education ,According to census 2011 report, the tribal literacy rate is only $59 \%$ where the overall literacy rate is $73 \%$. Gender wise and state wise tribal literacy also show a crucial image, Where Mizoram has the highest tribes literacy rate and Andhra Pradesh exists with lowest.

We all know that education is the fundamental right for all and it is the responsibility of the Govt. for provide it without any discrimination. But in real accessing education is far cry for million of children. A report published in 2017 in Telengana that more than half of total primary education enrolled child $(52.57 \%)$ are dropped out in 1-8 grades anong the Tribal communities(Times of India,2017). Keeping mind in this problem Government of India has started an innovative scheme for the motivated towards education of Scheduled Tribes, i.e., the establishment of Ashram schools, free of cost residential school etc. But still,the overall report in India is also not satisfactory.

So, In this aspect, many questions arises in our mind that How extent the govt. education related policy implemented successfully? Why dropped out rate is high among Tribes? What the precious literature said about this? For overall understanding this problem a review based study is very much necessary.

\section{OBJECTIVES OF THE STUDY}

It was aimed to provide a comprehensive understanding regarding the Tribal dropout based on 
the existing literature reporting govt. initiatives and reasons of dropout in India.

\section{MATERIALS AND METHODS}

For selecting article, search was done in Google scholar with searching keywords ranging date from January 1991 to December 2020. There are so many downloadable articles, and researcher was selected total 23 articles were found. After exclusion of repetition, screening, finally selection were done on the basis of inclusion and exclusion criteria.

\section{Searching Words}

1. Tribal dropout in India

2. Govt. initiatives for tribal education

\section{Inclusion Criteria}

1. Full downloadable article in PDF form

2. Searched done Google Scholar

3. Time January 1991 to December 2020

4. Articles those discussed on tribal education

5. English language.

Exclusion Criteria

1. Articles other than dropout topics

2. Article of tribal dropout outside the India demography.

\section{Data Characteristics}

Among the articles, there were 21 original articles, 3 news paper articles. Yearly distribution of article was 1991-3, 1993-1, 2004-1, 2009-1, 2011-1, 2012-1, 2014-4, 2016-2, 2017-3, 2018-4, 2020-2.

\section{BRIEF REVIEW POLICIES ON INDIAN GOVERNMENT}

After 73 years of independence, india still struggle with equity and equality related issues in education. Many childs are deprieved from the education in the name of caste, class, religion,creed, gender etc. When European countries achieve the Universalisation of Elementary Education goals, then India strives for $100 \%$ enrolment. The central and state govt. of India initiate and adopts different schemes, policies, project like SSA, Operation Black board, RTE act, Mid day Meal scheme etc. Article 21-A ensure that all the Childs can access free and compulsory education without any discrimination up to age of 14. Article 46 also provides that state shall be care of educational and economical interest of the weaker as well as Scheduled caste, Scheduled tribes sections.RTE act is a milestone of Indian education system and it ensure the free quality education with importance of mother tongue. $25 \%$ reservation even in private school for backward children with no detention and zero rejection. Many of tribal students became dropped out for unavailability of school within reasonable distance, poor economic condition and medum of instruction related problems. Thatswhy govt. under the SSA programme,DPEP,Operation blackboard scheme , a huge number of primary school was established within $1 \mathrm{~km}$ distance and upper primary school within $3 \mathrm{~km}$ distance, started Mid day meal scheme for giveng nutrition food which can also help for school retention and reduce dropout.Govt. provided post metric scholarship was started (1945) for encouraging tribal students towards professional, technical and non techinal courses with financial support. This scheme is totally $100 \%$ central govt. funded. Govt. also establish KGBV residential school in Backward districts for providing free of cost education for girls with accommodation and secuirity. Ministry of Tribal Affairs started Rajiv Gandhi National Fellowship Scheme (2005) with the help of UGC for financial support of completing higher education of tribal students.For making them economically efficient and self dependent, govt. opens Vocational training centres in tribal areas. Cental Govt. also give the scope for research in science and technology from abroad with full scholarship. Navodaya Vidyalayas also established with high infrastructures and trained teacher and providing all facilities for inculcate and bringout the rurau talent. Ashram school scheme(1991) was also started with a view to provide quality education with residential facility to ST students. Tribal students cannot be familiar with the science and technology based education if the syllabus is not linked with their culture. So, knowing their culture and understand them from their view point, total 14 tribal research institutes was established all over india. Except of these different state took different initiatives for providing quality education which help them for adjust with the modern society. But after all these, Tribal dropout problem still create the challenges for developing their communities. So, now we should know what are reasons behind their dropout after geting all types of support.

\section{STUDIES ON TRIBAL DROP OUT}

The Hindu (2018) indicates that Tribal dropout is increased after the school merging process under SATH-E project adopted by the NITI AYOG in tribal belt as a reason of low quality education. Students were dropout because govt. dont provide them financial support and medium of instruction is not the mother tongue. It also criticised that the government's took decision to stop funds for ashram schools without providing a viable alternative.

Narmadeswer Prased (1991) conducted a comparison study among the traditional and modern system and tribal higher education, found that the tribe's men want that type of education which may enables them to fit in to the modern world. Most of the students are dropping their education because the present syllabus and educational activities doesnot adjust with tribal culture. The author indicated that the tribe's men should concentrate more on skilled based occupations. Another important suggestion was, there should be setting up of special schools for 
them where adequate attention for them is ensured. Bairathi (1991) has examined the impact of education on tribal life has explored that the school condition in tribal areas are very much unsatisfactory. The unavailability of trained teacher, single teacher problems, low infrastructures of the schools, drinking water facilities, play ground, unavailability of smart classroom are create challenges at all time. In such a condition quality education cannot be attained. So, these leads them to demotivated from education and this force them to drop their study. He suggest that by improving the infrastructure facilities to improve the conditions of education can reduce the Drop-out. Sarangi.C (2009) also stated that most of the students were dropout due to the reason of low infrastructure facilities. Gadgil and Dandekar(1991) has studied about the problem of wastages (enrolled but not complete their primary education ) in tribal education by taking a batch of students in standard one in a given year following up in the subsequent years till the last grade are reached. They find that fifth Dropouts from school before completing the final grading of primary education constitutes wastes; and the incidence of wastage is computed from the proportion of Drop-out to the initial enrolment in the first grade. He reached the conclusion that special attention by the teacher to a great extent can remove drop out.

The National Council of educational Research and training conducted a seminar on tribal education in India (1993), discussed the various fields of tribal education like the facilities available, coverage, wastage and stagnation, utilization of financial assistance, basic problem of tribal education, socioeconomic problems, curriculum, methods and text books and the relative roles of Government and NGO in the education of tribal people. The seminar altogether has suggested a new revised curriculum for tribal education where tribal language got the importance by the teachers also is essential for the improvement in tribal educational attainment. Jay \& Srihari (2014) studied on Paniyan tribes of Kerala and explored that Most of the dropped out children are living with their parents who are dropped out and illiterate. Thats why unemployment and poverty problem is constant in their family. But now, with the help of different govt. schemes and awareness programme parents are aware that govt. want to upliftment their life style by providing the free and compulsory education. So, financial burden is not the cause of dropout, individual attitude is totally responsible for dropout problem. Against of this statement studies also identified that low socio economic status and negative parental attitude demotivate the students from education, as a result they are dropout(Mathur ,1999). Students think that if they are engage in any work which can reduce the financial burden of family is better than going to school (Gouda.S \& Sekhar,T.V, 2014). Basumatary
(2012) conducted a study on School dropout and found that various factors such as poverty level, distance of school from home, transport facilities, quality of teachers, social environment and many other factors are responsible for it. Chugh, (2011) supported this study and said that poverty, low educational level of parents the weak family structure, pattern of schooling of sibling and preschool experiences, family background and domestic problems were help to create the negative environment that are responsible for school dropout. Gautam, V. (2004) explained the reasons for high dropout among tribal students in his wrong medium of instruction, the appointment of non-tribal teachers in tribal areas and communication gap between the teachers and tribal children are the causes of high dropout rates in tribal schools.

\section{DISCUSSION ON REASON OF DROPOUT}

From the above literature it is proved that, Even govt. took the responsibility for free and compulsory education, food and accommodation, financial support for higher education But although the dropout rates continue to remain unacceptedly increasing specially among tribal students(Times of India,2017). Only one reason is not solely responsible for this, there are many factors which responsible for high dropout. Where we talks about girls education, Girls education can help self dependent, engage in job which can reduce family financial burden, Organise themselves, analyse the problematic situation for solve the problem, contribute for overall development which brought a huge change in society(I.E.D, 2020) but when we see the tribal education it lost its destination. So, we must briefly understand from the review, that what actually happened with them that why they leave from the school without complete the school education.

\section{Reasons of Drop out}

1. Language problem

Language related problem is one of the important problems for their drop out. Different tribal speaks different tribal language, but medium of instruction and teachers are sometimes unknown with this facts.

2. Unavailability of Books

Books are unavailable on their script and syllabus is not linked with their culture also a reason of school dropout.

3. Geographical Barrier

SSA, RTE act ensure the free and compulsory school education but due to the geographical barrier like location of village, hilly area, forest etc create a barrier for access the school education.

4. Poverty and unemployment 
Due to the low economic status poverty and unemployment is the another cause for school dropout. Childs are engaged for earning money rather than education.

5. Negative attitude towards education

Many more tribal parents are illiterate, school dropout and they think that sending the child to school is a luxurious activity. In other hand alcoholism of parents and peer influence also the reason of dropout (Soren.D, 2016).

6. First generation learner

A lot number of tribal first generation learner enrolled in school (Banerjee. J, 2013) but before completing the school they are dropped out due to the adjustment problems, academic support and illiterate parents.

7. Quality education

It is the another vital issue for dropout . different ASER report states the challenging faces of quality education specially in tribal area related to trained Teacher, language policy, unsuitable syllabus ,infrastructure, drinking water ,facility, are the causes of tribal dropout etc.

8. Caste Problem: According to census 2011, caste related problem is a problem for dropout of deprived child. They faces discrimination in all situation everyday at the school.

\section{CONCLUSION}

In this $21^{\text {st }}$ century when a tremendous development of science and technology thinks about the artificial intelligence, and make a society in another planet or space, then in another side a million of children struggle with fulfilment of their basic needs. Attaining minimum level of education is still of them out of mind. Our new education policy (2020) try to make smart classroom, online based teaching learning, create education hub, allow international universities for establish their new campus in India, but study explored equity and equality related issues faces challenges and a huge number of tribal children are out of school and deprived from accessing quality education. The time limit of sustainable development goals will complete by 2030 , but till now India is far away for achieving these. Govt. must give more concentration especially on tribal education where dropout rate and gender gap on literacy are very high, for achieving the selected educational development goals like RTE Act, UEE goals, which can help the development of their society as well as the nation. Establishment of many schools in tribal areas is not only solution for the problems, govt. give the importance on counselling programme of both students and parents,
Arrange awareness programme in ground level with the help of different NGOs, and volunteers, engage the stakeholders for supervising the overall activities which can help for the enroll and retention all the students in age appropriate class, for reducing dropout rate. More opportunities with easy access should be provided to the tribal children in order to bring those to the mainstream of economic development for fulfil the sustainable development goal.

\section{REFERENCES}

1. The Hindu (2018) published an article on "Dropout rate soaring after school mergers in tribal belts" August 18, 2018,retrieved from https://www.thehindu.com/news/national/dropout -rate-soaring-after-school-mergers-in-tribalbelts/article24727261.ece

2. Times of India (2017) published an article on "Dropout rate high among tribals, 'schools shut shop' 5th September, 2017; retrieved from https://timesofindia.indiatimes.com/city/hyderaba d/dropout-rate-high-among-tribals-schools-shut shop/articleshow/ 60371444.cms\#: :text $=$ In $\% 20$ class $\% \quad 201 \%$ 2D8\%2C\%20dropout,high\%20as\%20the\%20dat a\%20shows.

3. India Education Diary Bureau published article on Literacy among tribal Girls and women- "an overview", 14 august,2020, retrieved from https://indiaeducationdiary.in/literacy-among tribal-girls-and-women-an-overview/

4. Banerjee. J (2013) “ First Generation LearnersCaught Between Twoworlds: With Specific Reference To Scheduled Tribesof Ranibandh Block, Bankura" Paper Submitted for National Child Rights Research Fellowship2012-13.

5. Soren. D (2016) "Impact of interventions on school dropout menace among tribal children of Odisha state" Inter National Multi Disciplinary e-journal, ISSN-2277 4262, Vol-V, Issue-IV, Apr-2016. Page no.65

6. Gouda, S., \& T.V.Sekher. (2014). Factors Leading to School Dropouts in India: An Analysis of National Family Health Survey-3 Data. IOSR Journal of Research \& Method in Education (IOSR-JRME), 75-83.

7. Sarangi.C(2009) "The effect of psychosocial and institutional variables on school dropouts in the agegroup of 614 years with special reference to tribal children of Goalpara district”, Guahati University, retrieved from http://hdl.handle.net/10603/69834

8. Gov.t of India (2011). 2011 Cesus Report. New Delhi: Office of the Registrar General \& Census Commissioner

9. .Chugh, S. (2011). Dropout in secondary education: A study of children living in slums of Delhi. New Delhi: NUEPA.

10. Basumatary, R. (2012). School dropout across Indian states and UTs : An economic study. International research journal of social sciences, 1 (4), 28-35. 
11. Gautam, V. (2004). Education of Tribal Children in India and the Issue of Medium of Instruction: A Janshala Experience',http://www01.sil.org/asia/ldcl parallel papers /vinoba_gautam.pdf, accessed on 11/09/2016

12. Joy, J., \& Srihari, M. (2014). A case study on the school dropout scheduled tribal students of Wayanad District, Kerala. Research Journal of Educational Sciences, 2, 1-6. 